\title{
A systematic cost-effectiveness analysis of pregabalin in the management of fibromyalgia: an Iranian experience
}

\author{
Khosro Keshavarz ${ }^{1}$, Amir Hashemi-Meshkini ${ }^{1}$, Zahra Gharibnaseri ${ }^{1}$, Shekoufeh Nikfar ${ }^{1,2}$, \\ Abbas Kebriaeezadeh"1,3, Mohammad Abdollahi ${ }^{1,3}$
}

1Department of Pharmacoeconomics and Pharmaceutical Administration,
Faculty of Pharmacy and Pharmaceutical Policy Research Center, Tehran University
of Medical Sciences, Tehran, Iran
2Food and Drug Laboratory Research Center, Food and Drug Organization,
Ministry of Health and Medical Education, Tehran, Iran
3Department of Toxicology and Pharmacology, Faculty of Pharmacy, and Pharmaceutical
Sciences Research Center, Tehran University of Medical Sciences, Tehran, Iran

Submitted: 23 September 2012

Accepted: 2 November 2012

Arch Med Sci 2013; 9, 6: 961-967

DOI: 10.5114/aoms.2013.39617

Copyright (c) 2013 Termedia \& Banach

\author{
Corresponding author: \\ Prof. Mohammad Abdollahi \\ Tehran University \\ of Medical Sciences \\ Tehran 1417614411, Iran \\ Phone: +98 2164122319 \\ Fax: +9821 66959104 \\ E-mail: \\ mohammad.abdollahi@ \\ utoronto.ca
}

\begin{abstract}
Introduction: Fibromyalgia is a neuropathic syndrome which is more common in adult females. Pregabalin is the first medicine which was approved by the United States Food and Drug Administration for treatment of fibromyalgia. In this study we aimed to evaluate the cost-efficacy of pregabalin in the treatment of fibromyalgia in Iran.

Material and methods: To evaluate the efficacy of pregabalin, a systematic review was carried out by conducting a wide literature search for the main outcomes of interest that were pain score reduction from the baseline and the percentage of patients with more than $50 \%$ pain reduction. To evaluate costs of treatment, only the direct medical costs were considered. The calculated incremental cost-effectiveness ratio (ICER) were compared with one and three times the gross domestic product (GDP) per capita as the threshold to evaluate the economic condition of treatment to be "highly cost-effective", "cost-effective" or "not cost-effective".

Results: Out of 4012 searched reports, only four reports were included in the study, all of which were randomized controlled trials with placebo controls. The calculated ICERs for pregabalin $450 \mathrm{mg} /$ day and $600 \mathrm{mg} /$ day with both available forms of brand and generic medicines in the country were in the range of 44-1170 US dollars (USD) and 48-814 USD, which in all cases could be considered as highly cost-effective. Pregabalin $150 \mathrm{mg} /$ day based on available evidence does not have significant efficacy in comparison to placebo. But for pregabalin $300 \mathrm{mg} /$ day, no decision can be made based on current data.

Conclusions: Our analysis indicated that generic pregabalin in the treatment doses of $450 \mathrm{mg} /$ day and $600 \mathrm{mg} /$ day is highly cost-effective.
\end{abstract}

Key words: pregabalin, fibromyalgia, Lyrica, cost-effectiveness, systematic review, economic model, economic evaluation.

\section{Introduction}

Fibromyalgia is a worldwide chronic disease that is most common in adult females [1]. The prevalence of fibromyalgia in the United States (US) general population is about $2 \%$ [2] and in the UK is $2.8 \%$ [3]. Patients who 
suffer from fibromyalgia in Iran are estimated to constitute around $1.3 \%$ to $4 \%$ of the general population $[4,5]$. Widespread pain for more than 3 months and tenderness in some selected tender points are the main signs of fibromyalgia based on criteria of the American College of Rheumatology 1990 for diagnosis of fibromyalgia [6].

Some medications have been used to manage fibromyalgia in Iran and other countries including pain control medication, antidepressants [7], and nutritional supplements [8], none of which is approved for this indication. Pregabalin is the first medicine that was approved by the US Food and Drug Administration (FDA) in 2007 for fibromyalgia [9]. Currently duloxetine and milnacipran are also approved by the FDA for fibromyalgia $[10,11]$. The first one is available in Iran but in a very negligible volume and the second one is not available in the market because it has not been included in the Iranian Drug List (IDL).

The evidence indicates the considerable economic burden (2298 Canadian dollars only for direct medical costs) of fibromyalgia [12] both on patients and society [13], which has to be attended by policy makers in providing more cost-effective medicines and treatment strategy for the population. One of the important roles of government to implement the Iran national drug policy is to provide equal access for patients to essential drugs [14-16]. To put into operation this idea, affordability of medicines and balanced utilization of medicines should be achieved [17].

Pregabalin has recently become available in the Iranian market in both domestic generic and imported brand (Lyrica) forms. The price of pregabalin according to the Iranian drug basket could be considered high and is not currently covered by insurance. However, the results of economic evaluation for pregabalin in diabetic peripheral neuropathy in Iran showed that this drug is cost-effective in doses of $300 \mathrm{mg} /$ day or $600 \mathrm{mg} /$ day and they have been recommended to be added to the insurance coverage list [18] but cost-effectiveness of this drug for fibromyalgia has not been evaluated yet. Economic evaluation of medicines is a tool to assess national drug policy criteria such as accessibility and equity $[15,19]$

Table I. Details of criteria in study selection

\begin{tabular}{|ll|}
\hline Inclusion criteria & Exclusion criteria \\
\hline - Published papers in English language & - Unpublished studies \\
- One arm of pregabalin & - Proceedings \\
- Controlled studies & - Biochemical, pharmacokinetic and non-clinical studies \\
- Subject of fibromyalgia & - Animal studies \\
& - Phase 1 and 2 clinical trials without pregabalin arm \\
& - Uncontrolled studies \\
& - Observational studies \\
& - Review studies \\
& - Economic evaluation studies \\
\hline
\end{tabular}

Regarding the above statements, we aimed to analyze the cost-effectiveness of pregabalin in the treatment of fibromyalgia in comparison to other alternative treatments in Iran.

\section{Material and methods}

\section{Data sources}

To evaluate the efficacy of pregabalin in comparison to other alternatives, a systematic review of published studies was conducted. To cover all documents, databases of PubMed, Scopus, Google Scholar, and Cochrane were systematically searched using the keywords "fibromyalgia and pregabalin" and "fibromyalgia" from 1965 to 30 January of 2012. Published English language randomized controlled trial (RCT) studies which had pregabalin as one of their arms were included. Review articles, economic evaluation studies, studies on animals and observational studies were excluded. Full details of inclusion and exclusion criteria are presented in Table I. To evaluate cost of treatment with pregabalin, only the direct medical cost was considered in analysis, upon a clinical expert's opinion. Given that there are no considerable laboratory monitoring and diagnostic tests or other supplementary treatment strategy, we only considered the cost of medicines in the analysis. The treatment's cost was calculated based on the treatment period of included studies. The medical cost for both brand and generic products available in the Iranian market was calculated for every dose and each study. To calculate the cost of generic medicine we considered the cheapest combination of available dosage forms in Iran and for the brand ones we considered the most expensive combination. The exchange rate at the time declared by Iran's central bank was used to exchange Iranian rials (IRR) to US dollars (USD).

\section{Study selection}

The title and abstracts of search results were reviewed separately by two authors to eliminate duplicate studies, unrelated subjects and other exclusion criteria. Then the selected articles were double checked before inclusion in the study. In the 
next step, the full texts of selected studies were scrutinized and reviewed, which led to exclusion of some more studies.

\section{Quality assessment of included studies}

The methodological quality of each included study was assessed by the Jadad score, which gives every study a score between 0 and 5 based on descriptions of double-blindness, randomization and withdrawals [20]. Based on this method, studies with scores $\geq 3$ were considered as high quality and studies with scores $\leq 2$ were considered as low quality. In this study, a score less than 3 was considered as an exclusion criterion.

\section{Effects}

The outcome of interest for evaluation of efficacy was "pain score reduction from baseline". The pain score was calculated from an 11-point scale ( $0=$ no pain, $10=$ worse possible pain $)$ which was declared by the patients themselves for the last $24 \mathrm{~h}$. Some RCTs reported another outcome, "percentage of patients with at least $50 \%$ reduction in pain", which was included in our analysis as well.

\section{Incremental cost-effectiveness ratio}

Using the difference of cost and the difference in efficacy, the incremental cost-effectiveness ratio (ICER) for both brand and generic pregabalin in all treatment doses was calculated and parametric sensitivity analysis was performed using the confidence interval of efficacy in each study. The ICERs in this study were considered as the cost (USD) per one more score reduction in mean pain score in comparison to placebo or the cost (USD) needed to achieve one patient with more than $50 \%$ pain reduction. The ICERs were compared with both one and three times the gross domestic product (GDP) per capita upon recommendation of WHO-CHOICE [21] to evaluate whether the treatment of fibromyalgia with different evaluated doses is highly cost-effective (when the ICER was less than GDP per capita), cost-effective (when the ICER was between one and three times GDP per capita, or not cost-effective (when the ICER was more than three times GDP per capita), given that there is no accurate cost-effectiveness threshold (willingness to pay) calculated for health
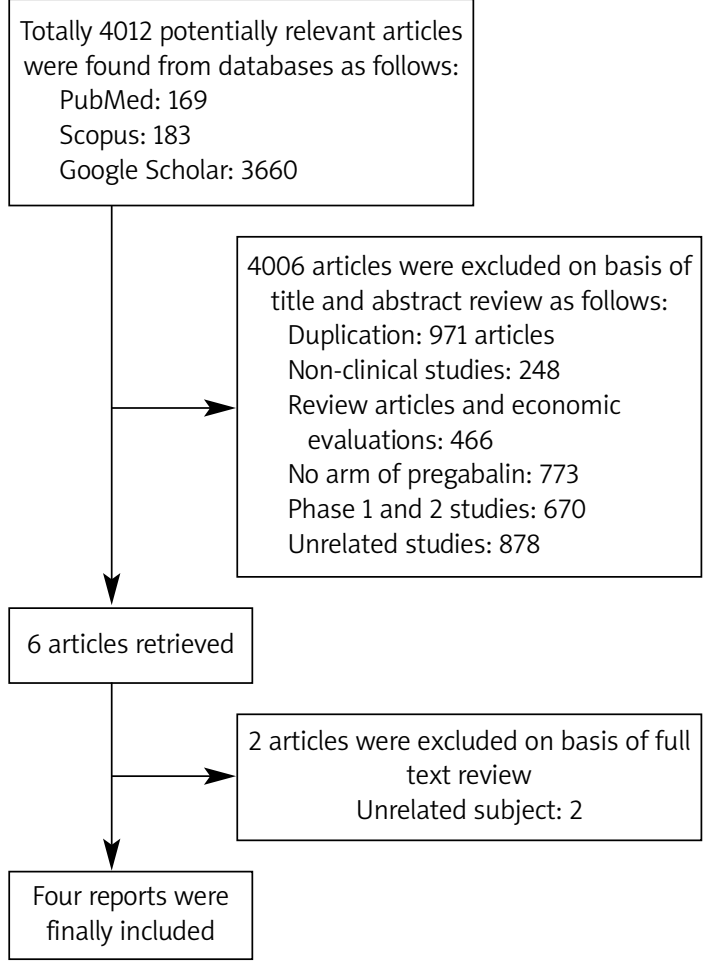

Figure 1. Flow of process in the selection of studies regarding the efficacy of pregabalin in fibromyalgia

care technologies in Iran. The GDP per capita based on the latest statistics released (2010) was 5608 USD [22]. It is notable that the Iranian pharmaco- and health economists estimate the threshold for Iran to be approximately two times the threshold (10 000 USD).

\section{Results}

Out of 4012 articles from the searched databases, 3660 articles were from Google Scholar, 169 articles were from PubMed, and the rest were from Scopus. After reviewing the title and abstract, 6 articles were included in the study, and from these articles, two were excluded after reviewing the full text because they were not RCTs (Figure 1). Finally, 4 RCTs were included in our analysis [23-26]. For all included articles, the Jadad score was calculated, which is illustrated in Table II. The patients in these included studies were men and women more than 18 years old who had met American College of Rheumatology criteria for fibromyalgia diagnosis

Table II. Jadad score to evaluate the quality of included studies

\begin{tabular}{|lcccc|}
\hline Author, year [reference] & Randomization & Double-blind & Withdrawal and dropout & Total score \\
\hline Crofford et al., 2005 [25] & 2 & 1 & 1 & 4 \\
\hline Arnold et al., 2008 [24] & 2 & 2 & 1 & 5 \\
\hline Mease et al., 2008 [23] & 1 & 1 & 1 & 3 \\
\hline Paure et al., 2011 [26] & 1 & 1 & 1 & 3 \\
\hline
\end{tabular}


Table III. Summarized characteristics of included studies

\begin{tabular}{|c|c|c|c|c|c|c|c|c|c|}
\hline \multirow{2}{*}{$\begin{array}{l}\text { Author, year } \\
\text { [reference] }\end{array}$} & \multicolumn{2}{|c|}{ No. of patients } & \multicolumn{4}{|c|}{ Age, mean \pm SD [years] } & \multirow[t]{2}{*}{ Dosage } & \multirow{2}{*}{$\begin{array}{c}\text { Concurrent } \\
\text { therapy }\end{array}$} & \multirow{2}{*}{$\begin{array}{l}\text { Duration } \\
\text { of study }\end{array}$} \\
\hline & Male & Female & & & & & & & \\
\hline \multirow{2}{*}{$\begin{array}{l}\text { Crofford } \\
\text { et al., } 2005 \\
{[25]}\end{array}$} & 45 & 484 & Placebo & Preg 150 & Preg 300 & Preg 450 & \multirow{2}{*}{$\begin{array}{c}\text { 150, } 300 \\
\text { and } 450 \\
\text { mg/day } \\
\text { three times } \\
\text { daily dosing }\end{array}$} & \multirow{2}{*}{$\begin{array}{c}\text { Prohibited } \\
\text { except for } \\
\text { acetamino- } \\
\text { phen, } \\
\text { aspirin } \\
\text { and anti- } \\
\text { migraines }\end{array}$} & \multirow[t]{2}{*}{8 weeks } \\
\hline & & & $49.7 \pm 10.7$ & $48.0 \pm 10.4$ & $47.7 \pm 10.1$ & $48.9 \pm 11.3$ & & & \\
\hline $\begin{array}{l}\text { Arnold et al., } \\
2008 \text { [24] }\end{array}$ & 41 & 704 & \multicolumn{4}{|c|}{$50.1 \pm 11.4$} & $\begin{array}{c}\text { 300, } 450 \\
\text { and } 600 \\
\text { mg/day } \\
\text { twice daily }\end{array}$ & Prohibited & 12 weeks \\
\hline \multirow{2}{*}{$\begin{array}{l}\text { Mease } \\
\text { et al., } 2008 \\
{[23]}\end{array}$} & \multirow[t]{2}{*}{42} & \multirow[t]{2}{*}{706} & \multicolumn{2}{|c|}{ Placebo } & \multicolumn{2}{|c|}{ Preg } & 300 and 450 & Prohibited & 12 weeks \\
\hline & & & \multicolumn{2}{|c|}{$48.6 \pm 11.3$} & \multicolumn{2}{|c|}{48.8} & $\begin{array}{l}\text { mg/day } \\
\text { twice daily }\end{array}$ & $\begin{array}{c}\text { acetamino- } \\
\text { phen) }\end{array}$ & \\
\hline \multirow{2}{*}{$\begin{array}{l}\text { Paure et al., } \\
2011 \text { [26] }\end{array}$} & 168 & 505 & Placebo & Preg 300 & Preg 450 & Preg 600 & \multirow{2}{*}{$\begin{array}{c}\text { 300, } 450 \\
\text { and } 600 \\
\text { mg/day } \\
\text { twice daily }\end{array}$} & \multirow{2}{*}{$\begin{array}{c}\text { Not } \\
\text { reported }\end{array}$} & \multirow[t]{2}{*}{14 weeks } \\
\hline & & & $48.1(11.3)$ & $48.4(10.8)$ & $48.0(11.3)$ & $49.6(11.3)$ & & & \\
\hline
\end{tabular}

Preg-pregabalin

and had a pain score of at least $40 \mathrm{~mm}$ of $100 \mathrm{~mm}$ on the pain visual analogue scale at screening and randomization. The characteristics of included articles are extracted and summarized in Table III. All selected articles were RCTs evaluating the efficacy of pregabalin in comparison to placebo and patients were randomly assigned to one of these groups in a double-blinded condition. The time period of treatment in the selected studies was 8-14 weeks and the dose of treatment was 300-600 mg/day. There was no report comparing pregabalin and other approved treatment for fibromyalgia. Because of diversity in reporting pain control outcomes, the pooling of results for efficacy was not possible; thus the extracted efficacy results regarding the treatment dose were presented separately.

\section{Pregabalin $150 \mathrm{mg} /$ day}

There was only one study evaluating pregabalin $150 \mathrm{mg} /$ day [25], which reported no significant efficacy for this dose in comparison to placebo. Thus the ICER for this dose was not calculated and this dose was considered as a dominated strategy (less or similar effectiveness but more cost).

\section{Pregabalin $300 \mathrm{mg} /$ day}

Concerning pregabalin $300 \mathrm{mg} /$ day, out of $4 \mathrm{stu}$ dies, 2 of them reported no significant efficacy in comparison to placebo $[25,26]$ in terms of pain score reduction. On the basis of two others $[19,20]$, the range of ICER for generic and brand pregabalin $300 \mathrm{mg} /$ day in treatment of fibromyalgia was 30117 and 309-1203, respectively (Table IV). This indicated that both generic and brand pregabalin $300 \mathrm{mg} /$ day could be considered as highly cost-effective treatment for fibromyalgia in Iran because their ICERs are less than GDP per capita. Also, one study that reported the efficacy of pregabalin according to the outcome of percentage of patients with more than $50 \%$ pain reduction [23] found that the ICER for generic and brand pregabalin $300 \mathrm{mg} /$ day was 428 and 4368, respectively (Table V). This means that both doses are highly cost-effective.

\section{Pregabalin $450 \mathrm{mg} /$ day}

Concerning pregabalin $450 \mathrm{mg} /$ day, the calculated ICER for generic and brand pregabalin was in the range of 44-132 and 393-1170, respectively [2326]. It showed that pregabalin $450 \mathrm{mg} /$ day in both generic and brand forms could be considered as highly cost-effective treatment compared with placebo (Table IV). Also there was one study that reported the efficacy of pregabalin $450 \mathrm{mg} /$ day according to the outcome of percentage of patients with more than $50 \%$ pain reduction [19] which resulted in the ICER of 771 and 6879 for its generic and brand forms, respectively (Table $\mathrm{V}$ ). This means that pregabalin $450 \mathrm{mg}$ /day in generic form is "highly cost-effective" but its brand form is "costeffective".

\section{Pregabalin $600 \mathrm{mg} /$ day}

Our analysis of pregabalin $600 \mathrm{mg} /$ day showed that except one study that reported no significant efficacy [26], the range of ICER for generic and brand pregabalin $600 \mathrm{mg} /$ day based on the other two studies $[23,24]$ is $48-115$ and $340-814$, respectively (Table IV). Also there was one study that 
Table IV. Summarized results for the studies with difference in mean pain score as outcome

\begin{tabular}{|c|c|c|c|c|c|c|}
\hline \multirow[t]{2}{*}{ Pregabalin } & \multirow{2}{*}{$\begin{array}{c}\text { Difference } \\
\text { in mean } \\
\Delta E(95 \% \mathrm{Cl})\end{array}$} & \multirow{2}{*}{$\begin{array}{c}\text { Cost } \\
\text { of treatment } \\
\text { (range-USD) }\end{array}$} & \multicolumn{2}{|c|}{$\begin{array}{l}\text { ICER } \\
\text { (range) }\end{array}$} & \multicolumn{2}{|c|}{$\begin{array}{l}\text { The consideration based on } \\
\text { comparison of ICER with threshold }\end{array}$} \\
\hline & & & Generic & Brand & Generic & Brand \\
\hline 150 mg/day [25] & * & $(14-116)$ & NA & NA & NA & NA \\
\hline 300 mg/day [24] & $0.71(-1.13,-0.29)$ & $(34-349)$ & $48(30-117)$ & 491 (309-1203) & $\mathrm{HCE}$ & HCE \\
\hline 300 mg/day [25] & * & $(23-233)$ & NA & NA & NA & NA \\
\hline 300 mg/day [23] & -0.43 & $(34-349)$ & 79 & 812 & HCE & HCE \\
\hline 300 mg/day [26] & * & $(34-349)$ & NA & NA & NA & NA \\
\hline 450 mg/day [24] & $0.98(-1.40,-0.57)$ & $(62-550)$ & 63 (44-109) & $561(393-965)$ & $\mathrm{HCE}$ & HCE \\
\hline 450 mg/day [25] & -0.93 & $(41-367)$ & 44 & 395 & HCE & HCE \\
\hline 450 mg/day [23] & -0.47 & $(62-550)$ & 132 & 1170 & $\mathrm{HCE}$ & $\mathrm{HCE}$ \\
\hline 450 mg/day [26] & -0.56 & $(62-550)$ & 111 & 982 & $\mathrm{HCE}$ & $\mathrm{HCE}$ \\
\hline 600 mg/day [25] & $1.00(-1.41,-0.59)$ & $(68-480)$ & $68(48-115)$ & $480(340-814)$ & $\mathrm{HCE}$ & HCE \\
\hline 600 mg/day [23] & -0.66 & $(68-480)$ & 103 & 727 & HCE & HCE \\
\hline 600 mg/day [26] & * & $(68-480)$ & NA & NA & NA & NA \\
\hline
\end{tabular}

${ }^{*}$ Non-significant results (95\% CI), NA - not applicable, HCE - highly cost-effective

Table V. Summarized results for the studies with percentage of patients with more than $50 \%$ pain reduction as outcome

\begin{tabular}{|c|c|c|c|c|c|c|}
\hline \multirow[t]{2}{*}{ Pregabalin } & \multirow{2}{*}{$\begin{array}{l}\text { Difference } \\
\text { in number } \\
\text { of patients } \\
\text { with } 50 \% \text { pain } \\
\text { reduction } \\
\text { (from } 100 \\
\text { patients) } \Delta E\end{array}$} & \multirow{2}{*}{$\begin{array}{c}\text { Cost } \\
\text { of treatment } \\
\text { in } 100 \\
\text { patients } \\
\text { (range - USD) }\end{array}$} & \multicolumn{2}{|c|}{ ICER } & \multirow{2}{*}{\multicolumn{2}{|c|}{$\begin{array}{l}\text { The consideration based on } \\
\text { comparison of ICER with threshold }\end{array}$}} \\
\hline & & & Generic & Brand & & \\
\hline 300 mg/day [23] & 8 & $(3426-34943)$ & 428 & 4368 & $\mathrm{HCE}$ & HCE \\
\hline 450 mg/day [23] & 8 & $(6166-55029)$ & 771 & 6879 & HCE & $\mathrm{CE}$ \\
\hline 600 mg/day [23] & 9 & $(6851-47961)$ & 761 & 5329 & $\mathrm{HCE}$ & $\mathrm{HCE}$ \\
\hline
\end{tabular}

CE - cost-effective, HCE - highly cost-effective

reported the efficacy of pregabalin $600 \mathrm{mg} /$ day according to the outcome of percentage of patients with more than $50 \%$ pain reduction [23]. The ICER for generic and brand forms of this medicine based on this study was 761 and 5329, respectively (Table V). Considering these results from included studies, pregabalin $600 \mathrm{mg} /$ day could be considered as highly cost-effective treatment for managing fibromyalgia in comparison to placebo.

\section{Discussion}

According to our analysis and based on available published evidence, pregabalin $150 \mathrm{mg}$ /day is not a cost-effective treatment because of non-significant efficacy in comparison to placebo. However, the available evidence for this dose was not sufficient to make an appropriate decision. Concerning pregabalin $300 \mathrm{mg} /$ day, there were some variations in the results of selected studies in terms of efficacy and cost-efficacy. Three out of 5 studies indicated that pregabalin in this treatment dose is high- ly cost-effective, but in 2 studies no significant efficacy was found. Making a decision about this dose would depend on the view of policymakers and existence of further evidence. Pregabalin $450 \mathrm{mg}$ / day according to the results of 3 out of 4 studies was highly cost-effective either with generic or brand forms. In addition, in one study, it was highly cost-effective in the generic form and cost-effective in the brand form. Pregabalin $600 \mathrm{mg} /$ day in both generic and brand forms was highly cost-effective for fibromyalgia regardless of one study which showed no significant efficacy for this dose.

It is notable that this is the first cost-efficacy analysis in the context of Iran concerning use of pregabalin in fibromyalgia. Given that pregabalin is the only approved medicine for management of fibromyalgia and its availability in Iran in both generic and brand forms, this analysis can be useful for policymakers and also healthcare providers to make appropriate evidence-based decisions in their areas of activity. 
Fibromyalgia is a disease which severely affects patients' quality of life, especially in women [27]. A study comparing quality of life in women with fibromyalgia with some other pain-related illnesses such as osteoarthritis, rheumatoid arthritis, permanent osteotomies, chronic obstructive pulmonary disease, and insulin-dependent diabetes showed that the quality of life in patients with fibromyalgia is among the lowest in all attributes [28]. Another study indicated that patients with fibromyalgia suffer from difficulties in personal relationships, jobs and mental health [29], and experience anxiety [30]. A cost-effectiveness analysis in the context of the UK [31] using Markov modeling for 1 year to evaluate pregabalin in the treatment of fibromyalgia showed that the cost per quality-adjusted life year (QALY) gained for using pregabalin compared to placebo was $£ 23,166$ and $£ 22,533$ for doses of $300 \mathrm{mg} /$ day and $450 \mathrm{mg} /$ day, respectively. They concluded that pregabalin is a cost-effective treatment. In another study in the US [32], a costeffectiveness analysis was conducted to compare different fibromyalgia management strategies by a decision-analytic model and indirect effectiveness comparison. The results indicated that pregabalin is cost-saving and more effective than placebo, duloxetine, tramadol, milnacipran, and gabapentin.

In our study, we did not use any decision tree or Markov model for economic evaluation of pregabalin in the treatment of fibromyalgia. In estimation of costs related to this treatment, only direct medical costs were taken into account and direct non-medical or indirect costs were excluded. Including these items, we can claim that pregabalin is a more cost-effective treatment.

Considering the present results, pregabalin $450 \mathrm{mg} /$ day and $600 \mathrm{mg} /$ day are recommended to be included in clinical practice guidelines and reimbursement schemes, given that there is no other FDA approved alternative available in the Iranian market. More accurate decisions about pregabalin $300 \mathrm{mg} /$ day need further evidence. Although pregabalin was cost-effective in both generic and brand forms, considering the bioequivalent efficacy of brand and generic forms, including pregabalin in the reimbursement positive list in the generic form would be more rational and cost-saving. Also more direct evidence regarding comparison of pregabalin and other approved medicines including duloxetine and milnacipran is needed to make the decision in a more efficient way.

In conclusion, based on the published available evidence and cost of pregabalin in Iran, pregabalin $450 \mathrm{mg} /$ day and $600 \mathrm{mg} /$ day can be recommended as a cost-effective treatment for fibromyalgia and can be included in clinical practice guidelines and insurance positive lists of Iran. The decision about pregabalin $300 \mathrm{mg} /$ day is dependent on the viewpoint of policymakers and future evidence. A final point is that more evidence on comparison of pregabalin and other approved or off-label alternatives in head-to-head trials is needed to make a more efficient, convincing decision.

\section{Acknowledgments}

The authors would like to appreciate the National Health Research Institute and Health Technology Assessment Department of the Iranian Ministry of Health and Medical Education for financial support of this study in part and also Dr Shekoufeh Alaee for her valuable consultation.

\section{References}

1. Russell IJ, Raphael KG. Fibromyalgia syndrome: presentation, diagnosis, differential diagnosis, and vulnerability. CNS Spectr 2008; 13: 6-11.

2. Wolfe F, Ross K, Anderson J, Russell IJ, Hebert L. The prevalence and characteristics of fibromyalgia in the general population. Arthritis Rheum 1995; 38: 19-28.

3. Branco JC, Bannwarth B, Failde I, et al. Prevalence of fibromyalgia: a survey in five European countries. Semin Arthritis Rheum 2009; 39: 448-53.

4. Forqanizade J, Abhari R, Shakibi MR, Pirozan M, Samadi F, Tavakoli-Bazaz S. Prevalence of rheumatoid in Tehran. J Iran Univ Med Sci 1995; 3: 182-91.

5. Naji A, Arab P. Prevalence of fibromyalgia syndrome in patients referring to Shariati hospital, Tehran. Tehran Univ Med J 2007; 64: 60-6.

6. Wolfe F, Smythe HA, Yunus MB, et al. The American College of Rheumatology 1990 criteria for the classification of fibromyalgia. Report of the multicenter criteria committee. Arthritis Rheum 1990; 33: 160-72.

7. Arnold LM. Biology and therapy of fibromyalgia. New therapies in fibromyalgia. Arthritis Res Ther 2006; 8: 212.

8. Merchant RE, Andre CA. A review of recent clinical trials of the nutritional supplement Chlorella pyrenoidosa in the treatment of fibromyalgia, hypertension, and ulcerative colitis. Altern Ther Health Med 2001; 7: 79-91.

9. US Food and Drug Administration. FDA Approves First Drug for Treating Fibromyalgia. Available from: http:// www.fda.gov/bbs/topics/NEWS/2007/NEW01656.html.

10. FDA Center for Drug Evaluation and Research. Approval duloxetine (Cymbalta). June 13, 2008. Available from: http://www.fda.gov/cder/foi/appletter/2008/ 022148s000ltr.pdf.

11. FDA Center for Drug Evaluation and Research. Approval milnacipran (Savella). January 13, 2009. Available from: http:// www.fda.gov/cder/foi/appletter/2009/022256ltr.pdf.

12. Penrod JR, Bernatsky S, Adam V, Baron M, Dayan N, Dobkin PL. Health services costs and their determinants in women with fibromyalgia. J Rheumatol 2004; 31: 1391-8.

13. Annemans L, Le Lay K, Charles T. Societal and patient burden of fibromyalgia syndrome. Pharmacoeconomics 2009; 27: 547-59.

14. AbdollahiasIA, Nikfar S, Kebriaeezadeh A, Dinarvand R, Abdollahi M. A model for developing a decision support system to simulate national drug policy indicators. Arch Med Sci 2011; 7: 744-6.

15. Nikfar S, Kebriaeezadeh A, Majdzadeh R, Abdollahi M. Monitoring of national drug policy (NDP) and its standardized indicators; conformity to decisions of the 
national drug selecting committee in Iran. BMC Int Health Hum Rights 2005; 5: 5.

16. Cheraghali AM, Nikfar S, Behmanesh Y, et al. Evaluation of availability, accessibility and prescribing pattern of medicines in the Islamic Republic of Iran. East Mediterr Health J 2004; 10: 406-15.

17. Nikfar S, Khatibi M, Abdollahiasl A, Abdollahi M. Cost and utilization study of antidotes: an Iranian experience. Int J Pharmacol 2011; 7: 46-9.

18. Hashemi Meshkini A, Keshvarz K, Gharinasseri Z, Nikfar S, Abdollahi M. The cost-effectiveness of pregabalin in the treatment of diabetic peripheral neuropathy: a systematic review and economic model. Int J Pharmacol 2012; 8: 490-5.

19. Nikfar S. A new model for decision analysis in economic evaluations of switchable health interventions. J Med Hypotheses Ideas 2012; 6: 12-5.

20. Jadad A. Randomized controlled trials. BMJ Books, London 1998.

21. World Health Organization, 2012. Choosing interventions that are cost effective (WHO-CHOICE).

22. World Economic Outlook Database, April 2012. International Monetary Fund. Accessed from http://www. imf.org/external/pubs/ft/weo/2012/01/weodata/index. aspx.

23. Mease PJ, Russell IJ, Arnold LM, et al. A randomized, double-blind, placebo-controlled, phase iii trial of pregabalin in the treatment of patients with fibromyalgia. J Rheumatol 2008; 35: 502-14.

24. Arnold LM, Russell IJ, Diri EW, et al. A 14-week, randomized, double-blinded, placebo-controlled monotherapy trial of pregabalin in patients with fibromyalgia. J Pain 2008; 9: 792-805.

25. Crofford LJ, Rowbotham MC, Mease PJ, et al. Pregabalin for the treatment of fibromyalgia syndrome results of a randomized, double-blind, placebo-controlled trial. Arthritis Rheum 2005; 52: 1264-73.

26. Pauer L, Winkelmann A, Arsenault $P$, et al. An international, randomized, double-blind, placebo-controlled, phase III trial of Pregabalin monotherapy in treatment of patients with fibromyalgia. J Rheumatol 2011; 38: 2643-52.

27. Roshan R, Shariatpanahi SS, Tavoli A, Qafori Z, FathiAshtiani A. Quality of life in women with fibromyalgia. Arch Med Sci 2009; 5: 267-70.

28. Burckhardt CS, Clark SR, Bennett RM. Fibromyalgia and quality of life: a comparative analysis. J Rheumatol 1993; 20: 475-9.

29. Bernald AL, Prince A, Edsall P. Quality of life issues for fibromyalgia patients. Arthritis Care Res 2000; 13: 42-50.

30. Pagano T, Matsutani LA, Ferreira EA, Marques AP, Pereira CA. Assessment of anxiety and quality of life in fibromyalgia patients. Sao Paulo Med J 2004; 122: 252-8.

31. Choy E, Richards S, Bowrin K, et al. Cost effectiveness of pregabalin in the treatment of fibromyalgia from a UK perspective. Curr Med Res Opin 2010; 26: 965-75.

32. Lloyd A, Boomershine CS, Choy EH, Chandran A, Zlateva G. The cost-effectiveness of pregabalin in the treatment of fibromyalgia: US perspective. J Med Econ 2012; 15: 481-92. 